\title{
Enhancing anaerobic digestion of agricultural residues by microaerobic conditions
}

Tsapekos, Panagiotis; Alvarado-Morales, Merlin; Kougias, Panagiotis G.; Treu, Laura; Angelidaki, Irini

Published in:

Biomass Conversion and Biorefinery

Link to article, DOI:

10.1007/s13399-019-00430-4

Publication date:

2021

Document Version

Peer reviewed version

Link back to DTU Orbit

Citation (APA):

Tsapekos, P., Alvarado-Morales, M., Kougias, P. G., Treu, L., \& Angelidaki, I. (2021). Enhancing anaerobic digestion of agricultural residues by microaerobic conditions. Biomass Conversion and Biorefinery, 11, 2325-2333. https://doi.org/10.1007/s13399-019-00430-4

\section{General rights}

Copyright and moral rights for the publications made accessible in the public portal are retained by the authors and/or other copyright owners and it is a condition of accessing publications that users recognise and abide by the legal requirements associated with these rights.

- Users may download and print one copy of any publication from the public portal for the purpose of private study or research.

- You may not further distribute the material or use it for any profit-making activity or commercial gain

- You may freely distribute the URL identifying the publication in the public portal 
Enhancing anaerobic digestion of agricultural-residues by microaerobic conditions

Panagiotis Tsapekos $^{\mathrm{a}} \cdot$ Merlin Alvarado-Morales $^{\mathrm{a}} \cdot$ Panagiotis G. Kougias $^{\mathrm{b}} \cdot$ Laura Treu $^{\mathrm{c}} \cdot$ Irini Angelidaki ${ }^{\mathrm{a}, *}$

${ }^{a}$ Department of Environmental Engineering, Technical University of Denmark, Kgs. Lyngby, DK-2800, Denmark

${ }^{\mathrm{b}}$ Institute of Animal Science, Hellenic Agricultural Organisation Demeter, Paralimni 58100, Greece

${ }^{\mathrm{c}}$ Department of Biology, University of Padova, Via U. Bassi 58/b, 35121, Padova, Italy

*Corresponding author: Irini Angelidaki, Department of Environmental Engineering, Technical University of Denmark, Bld 115, 2800 Lyngby, Denmark.

E-mail address: iria@env.dtu.dk, Tel.: +45 45251429 


\begin{abstract}
Biogas plants treating agricultural-residues are associated with limited bioenergy output due to the high content of hardly degradable lignocellulosic fibers in the feedstock. Hence, effective treatment techniques are needed to enhance holocellulose deconstruction, and thus, increase the energy budget of anaerobic digestion (AD) process. In the present research, microaerobic conditions were applied in reactors that were previously operated under strict anaerobic conditions as a tool to increase the biodegradability of the lignocellulosic material and thereby improve the methane production in lignocellulose-based AD. Initially, two levels of oxygen loads (i.e. 5 and $15 \mathrm{mLO}_{2} / \mathrm{gVS}$ ) were examined during the $\mathrm{AD}$ of lignocellulosic biomass at batch mode. Low and high oxygen loads were connected with positive $(+10 \%)$ and negative $(-4 \%)$ impact in methanation process, respectively. Subsequently, the experimental results were validated by the amended BioModel. Furthermore, continuous mode experiments were conducted to more closely mimic real-life applications. Monitoring of a continuous digester fed with agricultural residues showed that the injection of $7.3 \mathrm{mLO}_{2} / \mathrm{gVS} / \mathrm{d}-$ which value was defined from mathematical optimization -was capable of improving the methane yield by $\sim 7 \%$. In addition, oxygen injection did not create any risk of inhibition incidents. Concerning microbial community structure, the bacterial population was relatively robust and was not markedly affected by oxygen addition. In contrast, some archaeal representatives were found to have increased relative abundance on oxygen exposure. More specifically, the aero-tolerant Methanosarcina and Methanobacterium spp. were the most dominant methanogens at microaerobic conditions.
\end{abstract}

\title{
Keywords
}

Agricultural-residues; anaerobic co-digestion; microaerobic conditions; 16S rRNA gene sequences

\section{Introduction}

The recalcitrant phenolic structure of lignin is the major barrier that should be broken down in order to increase the access of fermentable organic matter to the microbes, and thus, increase the degradability of lignocellulosic residues [1]. For this reason, various pretreatment methods (i.e. physical, chemical, biological or combination of them) are available focusing on disrupting the naturally created protection shield [2]. Despite the vast diversity of alternative methods, most of the pretreatments are not very flexible 
and commonly need an extra process step before the anaerobic digestion (AD). In addition, the demand for this separate step is associated with extra costs for energy, equipment, facilities, construction and operation [3]. However, investments to address the mentioned needs can finally eliminate or overshadow the increased methane production. In contrast, the perspective of reducing the supply chain steps by performing an effective treatment in parallel with the biologically mediated AD process can improve the overall process balance [4].

In this context, the establishment of microaerobic conditions into an $\mathrm{AD}$ reactor appears as a promising solution to boost the methane yield of lignocellulosic biomass [5]. Specifically, oxygen can increase lignin oxidation due to the fact that the bacterial excretion of enzymes (e.g. laccases, peroxidases), which are able to break down the irregular polyphenolic polymer, is favored by the presence of oxygen [6]. These oxidative enzymes use oxygen as final electron acceptor to oxidize the phenolic hydroxyl groups of lignin [7, 8]. However, the oxygen should be carefully injected under a controlled environment to avoid substrate's overoxidation and loss of organic matter that can be conducted at a high oxidation-reduction potential [6].

Despite the fact that limited amounts of oxygen can increase the delignification of recalcitrant lignocellulosic residues, microaerobic conditions are not widely established in real-life applications. The reason behind is that a non-controlled oxygen addition can provoke strong inhibition to the sensitive methanogenic archaea leading to a markedly hindered methanation process [9]. On this topic, our preliminary study monitoring oxygen addition in $\mathrm{AD}$ culture showed that controlled operation can boost lignocellulose deconstruction and thus, increase the biogas production by $\sim 7 \%$ injecting $\mathrm{mLO}_{2} / \mathrm{gVS}$ [6]. However, the methane yield was deteriorated by $\sim 13 \%$, even by a slight increment on microaeration levels to $15 \mathrm{mLO}_{2} / \mathrm{gVS}$. Thus, the positive impact directly shifted to negative at higher oxygen loads that were inhibitory to methanogenic archaea. Nevertheless, the mentioned research did not assess the effect of oxygen on methane production in correlation with changes in microbial communities. Hence, a robust conclusion about the impact of oxygen on microbial and archaeal microbes cannot be drawn.

In addition, to better understand the biogas process at microaerobic conditions a deeper understanding of the basic kinetics is also needed. Each AD microbial group do not respond to the same extend on oxygen exposure, and hence, inhibition or stimulation of microbial growths and activities result in bioenergy output changes. Previously, attempts to model microaerobic conditions in AD process have focused almost exclusively on the extension of the ADM1 model to consider the oxygen effects on the different microbial 
groups as well as in the hydrolytic steps of AD [9]. The ADM1-Ox model proposed by Botheju et al. [10] includes seven aerobic uptake processes as well as oxygen effects on process kinetics. In this work the bioconversion "BioModel" developed by Angelidaki et al. [11] and later extended by Kovalovszki et al. [12] is used to model and simulate the effect of microaerobic conditions on the biodegradability of lignocellulosic feedstock.

The present study focuses on further paving the way for a successful implementation of microaerobic conditions in a strictly anaerobic environment. For this purpose, microaerobic conditions were initially established during the AD of straw and then, the amended BioModel was used to examine the effect of oxygen on biomass degradability. Subsequently, the co-digestion of straw with cattle slurry was performed under continuous mode operation injecting pure oxygen. The microbial community shifts were monitored by applying high throughput $16 \mathrm{~S}$ rRNA amplicon sequencing.

\section{Materials and methods}

\subsection{Inoculum and substrates characteristics}

Digestate from Snertinge biogas plant, which co-digests animal slurries and wastes from ethanol industry under thermophilic conditions, was used as inoculum. Before usage, the inoculum was sieved to remove large particles and the remaining undigested organic matter. Then, it was stored in a thermophilic incubator for ten days to decrease the background methanation. Wheat straw and cattle slurry were collected from a livestock farm in Denmark. The lignocellulosic substrate was treated with a cutting mill (SM 200, Retsch GmbH, Germany) to reach size distribution less than $0.5 \mathrm{~cm}$. In addition, cattle slurry was sieved to remove large lignocellulosic fibers that could create operational problems (i.e. clogging). The main physicochemical characteristics of the inoculum after storage and substrates after sieving and size decrease are presented in Table 1.

\subsection{Batch mode operation}

The effect of oxygen on the methane yield of lignocellulosic residues was initially examined in batch assays based on the guidelines of Angelidaki et al. [13]. Each reactor had a total and working volume of 547 and $200 \mathrm{~mL}$, respectively. The reactors were filled with $1 \mathrm{~g}$ wheat straw, $160 \mathrm{~mL}$ inoculum and $40 \mathrm{~mL}$ distilled water. The background methane productivity of the digestate was defined by blank reactors 
containing only water and inoculum. To evaluate the accuracy of the experiment, control reactors containing pure cellulose at the same organic load (i.e. $4.33 \mathrm{gVS} / \mathrm{L}$ ) were set up. Three different sets of straw-filled reactors were prepared based on oxygen levels: 0,5 and $15 \mathrm{mLO}_{2} / \mathrm{gVS}$, according to our previous research [6]. Oxygen was injected to the working volume of the reactors and the bottles were shaken daily to improve the oxygen mass transfer. Methane generation was measured every three days by sampling the headspace of the digesters until no significant increase $(\mathrm{p}<0.05)$ was detected. All batch reactors were conducted in triplicates.

\subsection{Continuous mode operation}

The effect of microaerobic conditions was examined by monitoring a continuously fed digester. The continuously stirred tank reactor (CSTR) had a total and working volume of 5.0 and $3.0 \mathrm{~L}$, respectively. The CSTR was operated under thermophilic conditions $\left(54 \pm 1^{\circ} \mathrm{C}\right)$, at hydraulic retention time (HRT) of 15 days and organic loading rate (OLR) of $1.7 \mathrm{gVS} / \mathrm{L} / \mathrm{d}$. The co-digestion of agricultural-residues was examined using cattle slurry and wheat straw. The feedstock composed of 85:15 slurry: straw on organic matter basis. The experimental period was separated in two periods. At the initial period (P-I, 0-15 days), the CSTR was operated under strictly anaerobic conditions. At the second period (P-II), microaerobic conditions were established (P-II, 16-45 days) by injecting $7.3 \mathrm{mLO}_{2} / \mathrm{gVS} / \mathrm{d}$ following the outcome of a thoroughly examined optimization study [6]. Specifically, response surface methodology was selected to describe the interactions of dissimilar variables (i.e. microaerobic period, oxygen load, pulse frequency). This methodology allowed the formulation of a second-order polynomial model and then, the optimal conditions that can maximize the methane yield were estimated. During the experiment, the biogas in the headspace was continuously recirculated to improve oxygen transfer to the liquid [14]. Biogas production was daily recorded using the water displacement method. Methane content in the biogas, $\mathrm{pH}$ and volatile Fatty acids (VFA) accumulation were measured twice a week.

\subsection{Microbial community analysis}

Samples $(50 \mathrm{~mL})$ were collected at steady-state of strictly anaerobic conditions (AD, 15th day) and steady-state of microaerobic period (MA, 45th day) in order to define the microbial changes due to oxygen injection. The sampling points are highlighted in red rhombus in Fig. 2a. PowerSoil@ DNA Isolation Kit 
(QIAGEN Bioinformatics, Germany) was used to isolate and purify the genomic DNA from samples. The guidelines of the manufacturer's protocol was followed with slight adjustments towards improved quality of the recovered DNA [15]. Sequencing of the 16S rRNA gene (V4 hypervariable region) was performed with universal primers 515F/806R by Illumina MiSeq desktop sequencer at the Ramaciotti Centre for Genomics (Sydney, Australia). NanoDrop (Thermo Scientific) and Qubit fluorimeter (Life Technologies) were to assess purity and quantification, respectively. The raw reads can be found in Sequence Read Archive (SRA) database (http://www.ncbi.nlm.nih.gov/sra) at an accession number of PRJNA354694. The detailed sample IDs along with statistics of sequencing are given in Supplementary material. The raw sequences were processed using CLC Workbench software (V.8.0.2) with Microbial genomics module plug in (QIAGEN) and analyzed as previously described [15]. The most abundant operational taxonomic units (OTUs) are presented in the Supplementary Dataset and the consensus sequences were manually verified using BLAST (16S ribosomal RNA database) using previously defined threshold for taxonomic assignment [16]. The Multi experiment viewer software was used to depict the relative abundance of microbial members as heat map (MeV 4.9.0) with Pearson correlation with complete linkage method for OTUs clustering [17].

\subsection{Analytical methods}

The values of $\mathrm{pH}, \mathrm{TS}, \mathrm{VS}, \mathrm{TKN}$ and $\mathrm{NH}_{4}^{+}$were defined according to Standard methods for the examination of water and wastewater [18]. The methane concentration in all AD reactors and the VFA content in all samples were determined using gas-chromatographers (GC-TRACE, Thermo Scientific), as previously described [19]. All analyses were performed in triplicate samples.

\subsection{Modelling approach and computational method}

Due to the nature of the substrate, oxygen effect is considered solely to affect the carbohydrate fraction of the substrate. Similar to the approach suggested by de Gracia et al. [20], a first order aerobic hydrolysis kinetic equation for insoluble carbohydrates $\left(\mathrm{C}_{6} \mathrm{H}_{10} \mathrm{O}_{5}\right)_{i s}$ was incorporated into the BioModel to model the oxygen effects on this hydrolytic step (1.1) 


$$
r_{a e, h y d_{\text {_carb }}}=k_{0, a e}\left(\frac{K_{i}}{\Sigma V F A+K_{i}}\right)\left(\frac{1}{1+\frac{K_{s, O_{2}}}{\left[O_{2}\right]}}\right)\left[\left(C_{6} H_{10} O_{5}\right)_{i s}\right]
$$

Where $k_{0, a e}$ is the maximum specific hydrolysis rate constant for carbohydrates under aerobic conditions. Inhibition due to oxygen concentration -not represented in the original BioModel -was incorporated by means of a non-competitive inhibition term and it was considered to affect the anaerobic hydrolysis, acidogenic, lipolytic, acetogenic and aceticlastic methanogenic steps, respectively (1.2-1.8)

$$
\begin{aligned}
& r_{\text {hyd_carb }}=k_{0}\left(\frac{K_{i}}{\Sigma V F A+K_{i}}\right)\left(\frac{1}{1+\frac{\left[O_{2}\right]}{K_{i, O_{2}}}}\right)\left[\left(C_{6} H_{10} O_{5}\right)_{i s}\right] \\
& r_{\text {Carb }}=\mu_{\text {max }, \text { Carb }}(T)\left(\frac{1}{1+\frac{K_{s, \text { Carb }}}{\left[\left(C_{6} H_{10} O_{5}\right)_{s}\right]}}\right)\left(\frac{1}{1+\frac{K_{s, N H_{3}}}{\left[T-N H_{3}\right]}}\right)\left(\frac{1}{1+\frac{[L C F A]}{K_{i, L C F A}}}\right)\left(\frac{1}{1+\frac{\left[O_{2}\right]}{K_{i, O_{2}}}}\right) X_{\text {Carb }} F(p H) \\
& r_{A A}=\mu_{\max , A A}(T)\left(\frac{1}{1+\frac{K_{s, A A}}{[A A]}}\right)\left(\frac{1}{1+\frac{[L C F A]}{K_{i, L C F A}}}\right)\left(\frac{1}{1+\frac{\left[O_{2}\right]}{K_{i, O_{2}}}}\right) X_{A A} F(p H) \\
& r_{G T O}=\mu_{\text {max }, \text { GTO }}(T)\left(\frac{1}{1+\frac{K_{s, G T O}}{[G T O]}}\right)\left(\frac{1}{1+\frac{K_{s, N H_{3}}}{\left[T-N H_{3}\right]}}\right)\left(\frac{1}{1+\frac{[L C F A]}{K_{i, L C F A}}}\right)\left(\frac{1}{1+\frac{\left[O_{2}\right]}{K_{i, O_{2}}}}\right) X_{G T O} F(p H) \\
& r_{L C F A}=\mu_{\max , L C F A}(T)\left(\frac{1}{1+\frac{K_{s, L C F A}}{[L C F A]}+\frac{[L C F A]}{K_{i, L C F A}}}\right)\left(\frac{1}{1+\frac{K_{s, N H_{3}}}{\left[T-N H_{3}\right]}}\right)\left(\frac{1}{1+\frac{\left[O_{2}\right]}{K_{i, O_{2}}}}\right) X_{L C F A} F(p H) \\
& r_{A}=\mu_{\max , A}(T)\left(\frac{1}{1+\frac{K_{s, A}}{[A]}}\right)\left(\frac{1}{1+\frac{K_{s, N H_{3}}}{\left[T-N H_{3}\right]}}\right)\left(\frac{1}{1+\frac{[H A c]}{K_{i, H A c}}}\right)\left(\frac{1}{1+\frac{[L C F A]}{K_{i, L C F A}}}\right)\left(\frac{1}{1+\frac{\left[O_{2}\right]}{K_{i, O_{2}}}}\right) X_{A} F(p H)
\end{aligned}
$$




$$
r_{H A c}=\mu_{\text {max }, H A c}(T)\left(\frac{1}{1+\frac{K_{s, H A c}}{[H A c]}}\right)\left(\frac{1}{1+\frac{K_{s, N H_{3}}}{\left[T-N H_{3}\right]}}\right)\left(\frac{1}{1+\frac{\left[N H_{3}\right]}{K_{i, N H_{3}}}}\right)\left(\frac{1}{1+\frac{[L C F A]}{K_{i, L C F A}}}\right)\left(\frac{1}{1+\frac{\left[O_{2}\right]}{K_{i, O_{2}}}}\right) X_{H A c} F(p H)
$$

Aerobic uptake of soluble carbohydrates was represented by the following stoichiometry (1.9)

$$
\left(\mathrm{C}_{6} \mathrm{H}_{10} \mathrm{O}_{5}\right)_{s}+\mathrm{NH}_{3}+\mathrm{O}_{2} \rightarrow \mathrm{C}_{5} \mathrm{H}_{7} \mathrm{O}_{2} \mathrm{~N}+\mathrm{CO}_{2}+3 \mathrm{H}_{2} \mathrm{O}
$$

Monod type kinetic was used to model the aerobic process for soluble carbohydrates degradation according to equation (1.10)

$$
r_{\text {ae, } C \text { arb }}=\mu_{\text {max }, \text { Carb }}(T)\left(\frac{1}{1+\frac{K_{s, C a r b, A e}}{\left[\left(C_{6} H_{10} O_{5}\right)_{s}\right]}}\right)\left(\frac{1}{1+\frac{K_{s, N H_{3}}}{\left[T-N H_{3}\right]}}\right)\left(\frac{1}{1+\frac{[L C F A]}{K_{i, L C F A}}}\right)\left(\frac{1}{1+\frac{K_{s, O_{2}}}{\left[O_{2}\right]}}\right) X_{C a r b} F(p H)(1.10)
$$

Where $X$ represents the concentration of the different biomass-microbial groups in the BioModel. Values for the new parameters, $k_{0, a e}, K_{i, O 2}$, and $K_{s, O 2}$ were identified by minimization of the square-error criteria between the BioModel output and the experimental data. The Levenberg-Marquardt algorithm [21] was used to solve the non-linear least square minimization problem. Methane cumulative production under the different microaerobic experimental conditions was used to perform the parameter estimation. Gaseous component $\left(\mathrm{CH}_{4}, \mathrm{CO}_{2}, \mathrm{NH}_{3}, \mathrm{H}_{2} \mathrm{~S}\right.$, and $\left.\mathrm{O}_{2}\right)$ in liquid and gas phases were modeled as described in Lovato et al. [22].

\subsection{Statistics}

ANOVA accompanied with a Post Hoc test (Tukey HSD) was conducted using OriginPro 9.0.0 SR2 software to define statistically significant differences $(\mathrm{p}<0.05)$ among experimental measurements. In addition, descriptive statistics was performed for all variables; mean values and standard deviations were computed. 


\section{Results and discussion}

\subsection{Batch \& model simulation results}

Initially, batch assays were conducted to evaluate the effect of oxygen on lignocellulose degradability and the experimental measurements were validated by the amended BioModel. First, for the anaerobic conditions experiment (Fig. 1a) the maximum specific hydrolysis rate constant and biodegradability coefficient for carbohydrates, respectively were the only parameters considered for the model calibration (Table 2). Subsequently, the parameters were fixed and then, the experimental data-sets of both microaerobic conditions were used to estimate the new set of parameters, $k_{0, a e}, K_{i, O 2}$, and $K_{s, O 2}$. As observed in Fig. 1b, c model-fitting results exhibited a good agreement with experimental data.

The experimental results showed that both microaerobic conditions affected the cumulative methane production (Fig. 1b, c). The oxygen load of $5 \mathrm{mLO}_{2} / \mathrm{gVS}\left(31 \mathrm{mgO}_{2} / / \mathrm{L}\right)$ had a positive impact $(+10 \%)$, whilst the $15 \mathrm{mLO}_{2} / \mathrm{VS}$ (93 $\mathrm{mg} \mathrm{O}_{2} / / \mathrm{L}$ ) had a negative one (-4\%), when compared to the control experiment (Fig. 1a), respectively. It has been documented that when using mono-saccharide as substrate, oxygen loads of 44 and $88 \mathrm{mg} / \mathrm{L}$ had a negligible but negative impact on the methane generation potential [23]. In this study, straw was used as substrate and therefore an effect on the hydrolysis due to aerobic activity of facultative microorganisms could be expected, but not necessarily in the ultimate methane potential as reported in other studies [24]. This can be observed in Fig. 2a which represents the concentration of the soluble carbohydrates -a hydrolytic product - over time for the anaerobic and microaerobic experimental conditions, respectively.

The maximum value of the soluble carbohydrates attained ultimately, corresponding to an enhancement of $15 \%$ in the hydrolytic pathway provoked by the microaerobic conditions of $15 \mathrm{mLO}_{2} / \mathrm{gVS}$ (Fig. 2b). This is expected as the increased hydrolysis rate is directly linked with the oxygen load as observed in Fig. 3c. Once the oxygen is depleted, there is a shift after five days to anaerobic conditions again.

\subsection{Effect of microaerobic conditions in continuous mode operation}

The co-digestion of straw with livestock slurry was conducted in a lab-scale CSTR and the outcome measures from reactor's monitoring are depicted in Fig. 3. At steady-state conditions of P-I, the methane 
in the biogas was $70.2 \pm 0.3 \%$ and the bioenergy yield was $259 \pm 5 \mathrm{mLCH}_{4} / \mathrm{gVS}$ (Fig. 2a). In parallel, pH was stable at $7.93 \pm 0.06$, while negligible accumulation of TVFA was observed $(0.11 \pm 0.01 \mathrm{~g} / \mathrm{L})$ (Fig. 3b). Subsequently, $7.3 \mathrm{mLO}_{2} / \mathrm{gVS}$ were daily injected to reactor's working volume for the entire P-II.

During the first HRT of microaerobic conditions, the methane production was not affected. However, during the second HRT the impact of oxygen was revealed and at the newly established steady-state the methane yield was $276 \pm 7 \mathrm{mLCH}_{4} / \mathrm{gVS}$ or $7 \%$ higher than that of the anaerobic operation (i.e. P-I). In parallel, the methane concentration in biogas $(69.9 \pm 1.1 \%), \mathrm{pH}(7.92 \pm 0.09)$ and TVFA $(0.08 \pm 0.01 \mathrm{~g} / \mathrm{L})$ stayed at the same range with the strictly AD. Hence, an acclimation period was mandatory for the microorganisms to be adapted into the new conditions. It should be noted that the results do not differ significantly $(\mathrm{p}>0.05)$ with the outcome of our previous study [6], in which the optimization model predicted a 9\% increase in methanation process using comparable oxygen injection load. Monitoring the biochemical parameters showed that the methane production of lignocellulose-based AD was favored by the applied microaerobic conditions. It is indicated that the injected oxygen concentrations were not able to partially or totally inhibit the $\mathrm{AD}$ of agricultural residues.

\subsection{Effect of microaerobic conditions on microbial populations}

Alpha diversity estimated the OTUs diversity and the rarefaction curves indicated that the sequencing data were satisfactory to deliver all the adequate information for the content of microbial communities (Supplementary Data). In addition, principal coordinate analysis was conducted to evaluate composition and variability of microorganisms (Supplementary Data).

Regarding bacterial population, the most abundant strains belonged to Firmicutes and Bacteroidetes phyla, which commonly dominate biogas reactors treating similar agricultural residues [25, 26]. In both samples, the most dominant OTU was Clostridia sp. 20, affiliated to Firmicutes (Fig. 4). Conducting a BLASTn search to the NCBI database of $16 \mathrm{~S}$ ribosomal RNA sequences for both bacteria and archaea, the strain was found to be only $90 \%$ similar to Hydrogenispora ethanolica of class Clostridia.

The dominance of Clostridia into biogas reactors treating livestock slurry has been previously reported in the literature $[27,28]$. At the end of the experiment (i.e. 2 HRTs of microaerobic conditions), Clostridia sp. 85 of Ruminococcaceae family increased its relative abundance by 12.5 -fold. Species able to decompose structural sugars are known within Ruminococcaceae family, due to their characteristics to excrete enzymes 
which can hydrolyse the glycosidic bonds in complex carbohydrates and other components of carbohydrateactive enzymes that help the colonization in lignocellulose-based biogas reactors $[29,30]$. Nevertheless, the establishment of microaerobic environment did not create distinct shifts in the global bacterial consortium. A rational to explain the lack of remarkable changes can be attributed to the fact that a large fraction of the detected bacteria are facultative anaerobes. Hence, they can use the exogenous oxygen and rapidly reestablish the anaerobic environment avoiding the colonization obligatory aerobic bacteria. Furthermore, the long-term operation of the $\mathrm{AD}$ reactor could also contribute in a relative establishment of a robust and adapted to the feedstock bacterial community.

On the other hand, interesting findings were associated with the archaeal consortium (Fig. 4b). For instance, Methanosarcina thermophila 1 (100\% similarity), which dominated the methanogenic population in both samples, increased its relative abundance by 6.3 -fold at microaerobic environment. Likewise, Methanosarcina sp. 8 was also found to be enhanced by 6.2 -fold at the end of the experiment. The increased proliferation is attributed to the fact that Methanosarcina spp. are among the most aero-tolerant methanogens [9]. Furthermore, Methanobacterium sp. 17 was also favored during oxygenation conditions, which is in agreement with a previous research that detected increased abundance of Methanobacterium under comparable oxygen exposure levels [31]. In contrast, Methanoculleus palmolei 4 and Methanothermobacter thermautotrophicus 5 were inhibited and decreased their relative abundance by 7.8and 37.0-fold, respectively. In accordance, $\mathrm{Fu}$ et al. [31] found that the relative abundance of Methanoculleus and Methanothermobacter was decreased under oxygenated conditions. In addition, the abundance of M. palmolei 2 remained unchanged during the entire experiment indicating oxygen tolerance. This is in accordance with previous report that found M. palmolei species to be tolerant to microaerobic [32] or aerobic conditions [33].

\section{Conclusions}

The present research demonstrated that controlled oxygen exposure can boost the methane production of agricultural residues. The amended BioModel was used to analyze the effect of oxygen on biomass degradability and to obtain a set of parameters for further experimental validation. Therefore, results from BioModel should be interpreted as qualitative indication of the effect of microaerobic conditions in the methanation process and not as absolute guidelines of oxygen loads that could enhance the hydrolytic 
pathway. At continuous mode operation, the anaerobic digestion of agricultural residues was enhanced by $7 \%$ by the injection of $7.3 \mathrm{mLO}_{2} / \mathrm{gVS} / \mathrm{d}$. Moreover, the microbial analysis showed that the bacterial consortium was not markedly affected by the microaerobic conditions. Regarding methanogenic populations, the aero-tolerant Methanosarcina thermophila increased its relative abundance and efficiently carried out the methanogenesis step under the limited oxygen exposure. The findings of the present study indicate that controlled microaerobic condition can be considered as an effective tool to improve the bioenergy output of lignocellulose-based biogas production.

\section{Acknowledgement}

The authors would like to acknowledge financial support by the Danish Agency of Energy program under EUDP "New technology for an efficient utilization of meadow grass in biogas reactor"-contract 640130159.

\section{References}

1. Rajendran K, Drielak E, Sudarshan Varma V, et al (2018) Updates on the pretreatment of lignocellulosic feedstocks for bioenergy production-a review. Biomass Convers Biorefinery 8:471-483. https://doi.org/10.1007/s13399-017-0269-3

2. Čater M, Zorec M, Marinšek Logar R (2014) Methods for Improving Anaerobic Lignocellulosic Substrates Degradation for Enhanced Biogas Production. Springer Sci Rev 2:51-61. https://doi.org/10.1007/s40362-014-0019-x

3. Nanda S, Mohammad J, Reddy SN, et al (2014) Pathways of lignocellulosic biomass conversion to renewable fuels. Biomass Convers. Biorefinery

4. Tsapekos P, Kougias PG, Egelund H, et al (2017) Improving the energy balance of grass-based anaerobic digestion through harvesting optimisation. Anaerobe 46:131-137

5. Jagadabhi PS, Kaparaju P, Rintala J (2010) Effect of micro-aeration and leachate replacement on COD solubilization and VFA production during mono-digestion of grass-silage in one-stage leach-bed reactors. Bioresour Technol 101:2818-2824 
6. Tsapekos P, Kougias PG, Vasileiou SA, et al (2017) Effect of micro-aeration and inoculum type on the biodegradation of lignocellulosic substrate. Bioresour Technol 225:246-253

7. Brown ME, Chang MCY (2014) Exploring bacterial lignin degradation. Curr Opin Chem Biol 19:1-7. https://doi.org/10.1016/j.cbpa.2013.11.015

8. Jurado MM, Suarez-Estrella F, Lopez MJ, et al (2015) Enhanced turnover of organic matter fractions by microbial stimulation during lignocellulosic waste composting. Bioresour Technol 186:15-24. https://doi.org/10.1016/j.biortech.2015.03.059

9. Botheju D, Bakke R (2011) Oxygen Effects in Anaerobic Digestion - A Review. Open Waste Manag J 4:1-19. https://doi.org/10.2174/1876400201104010001

10. Botheju D, Lie B, Bakke R (2010) Oxygen effects in anaerobic digestion. Model Identif Control 31:55-65. https://doi.org/10.4173/mic.2010.2.2

11. Angelidaki I, Ellegaard L, Ahring BK (1999) A comprehensive model of anaerobic bioconversion of complex substrates to biogas. Biotechnol Bioeng 63:363-372

12. Kovalovszki A, Alvarado-Morales M, Fotidis IA, Angelidaki I (2017) A systematic methodology to extend the applicability of a bioconversion model for the simulation of various co-digestion scenarios. Bioresour Technol 235:157-166

13. Angelidaki I, Alves M, Bolzonella D, et al (2009) Defining the biomethane potential (BMP) of solid organic wastes and energy crops: a proposed protocol for batch assays. Water Sci Technol $59: 927$

14. Bassani I, Kougias PG, Treu L, et al (2017) Optimization of hydrogen dispersion in thermophilic up-flow reactors for ex-situ biogas upgrading. Bioresour Technol 234:310-319

15. Treu L, Kougias PG, de Diego-Díaz B, et al (2018) Two-year microbial adaptation during hydrogen-mediated biogas upgrading process in a serial reactor configuration. Bioresour Technol 264:140-147. https://doi.org/10.1016/j.biortech.2018.05.070

16. Yarza P, Yilmaz P, Pruesse E, et al (2014) Uniting the classification of cultured and uncultured 
bacteria and archaea using 16S rRNA gene sequences. Nat Rev Microbiol 12:635-645

17. Howe E, Holton K, Nair S, et al (2010) MeV: MultiExperiment Viewer. In: Ochs MF, Casagrande JT, Davuluri R V (eds) Biomedical Informatics for Cancer Research. Springer US, Boston, MA, pp 267-277

18. APHA (2005) Standard Methods for the Examination of Water and Wastewater. American Public Health Association, Washington, DC, USA

19. Khoshnevisan B, Tsapekos P, Alvarado-Morales M, Angelidaki I (2018) Process performance and modelling of anaerobic digestion using source-sorted organic household waste. Bioresour Technol 247:486-495

20. de Gracia M, Grau P, Huete E, et al (2009) New generic mathematical model for WWTP sludge digesters operating under aerobic and anaerobic conditions: Model building and experimental verification. Water Res. https://doi.org/10.1016/j.watres.2009.07.014

21. Press WH, Teukolsky S, Vetterling W (2002) Numerical recipes in C (2nd ed.): the art of scientific computing

22. Lovato G, Alvarado-Morales M, Kovalovszki A, et al (2017) In-situ biogas upgrading process: Modeling and simulations aspects. Bioresour Technol 245:. https://doi.org/10.1016/j.biortech.2017.08.181

23. Botheju D, Lie B, Bakke R (2009) Oxygen Effects in Anaerobic Digestion. Identif Control 30:191-201. https://doi.org/10.4173/mic.2009.4.1

24. Johansen JE, Bakke R (2006) Enhancing hydrolysis with microaeration. Water Sci Technol 53:43-50. https://doi.org/10.2166/wst.2006.234

25. Sun L, Liu T, Müller B, Schnürer A (2016) The microbial community structure in industrial biogas plants influences the degradation rate of straw and cellulose in batch tests. Biotechnol Biofuels 9:1-20

26. Tuan NN, Chang YC, Yu CP, Huang SL (2014) Multiple approaches to characterize the microbial 
community in a thermophilic anaerobic digester running on swine manure: A case study.

Microbiol Res 169:717-724

27. Tsapekos P, Kougias PG, Vasileiou SA, et al (2017) Bioaugmentation with hydrolytic microbes to improve the anaerobic biodegradability of lignocellulosic agricultural residues. Bioresour Technol 234:350-359

28. Tsapekos P, Kougias PG, Treu L, et al (2017) Process performance and comparative metagenomic analysis during co-digestion of manure and lignocellulosic biomass for biogas production. Appl Energy 185:126-135

29. Langer SG, Ahmed S, Einfalt D, et al (2015) Functionally redundant but dissimilar microbial communities within biogas reactors treating maize silage in co-fermentation with sugar beet silage. Microb Biotechnol 8:828-836

30. Kougias PG, Campanaro S, Treu L, et al (2018) Spatial distribution and diverse metabolic functions of lignocellulose-degrading uncultured bacteria as revealed by genomecentric metagenomics. Appl Environ Microbiol 84:. https://doi.org/10.1128/AEM.01244-18

31. Fu SF, Wang F, Shi XS, Guo RB (2016) Impacts of microaeration on the anaerobic digestion of corn straw and the microbial community structure. Chem Eng J 287:523-528. https://doi.org/10.1016/j.cej.2015.11.070

32. Ruan R, Cao J, Li C, et al (2017) The influence of micro-oxygen addition on desulfurization performance and microbial communities during waste-activated sludge digestion in a rusty scrap iron-loaded anaerobic digester. Energies. https://doi.org/10.3390/en10020258

33. Sang NN, Soda S, Ishigaki T, Ike M (2012) Microorganisms in landfill bioreactors for accelerated stabilization of solid wastes. J. Biosci. Bioeng. 


\section{Tables}

Table 1 Characteristics of inoculum, wheat straw and cattle slurry

\begin{tabular}{lllll}
\hline Characteristics & Unit & Inoculum & Wheat Straw & Cattle slurry \\
\hline $\mathrm{pH}$ & & 8.11 & & 7.69 \\
Total Solids (TS) & $\mathrm{g} / \mathrm{kg}$ & $27.47 \pm 0.24$ & $928.40 \pm 5.90$ & $31.82 \pm 0.52$ \\
Volatile solids (VS) & $\mathrm{g} / \mathrm{kg}$ & $17.11 \pm 0.12$ & $867.20 \pm 3.90$ & $22.13 \pm 0.23$ \\
Total Kjeldahl Nitrogen (TKN) & $\mathrm{g} / \mathrm{kg}$ & $3.63 \pm 0.13$ & $4.82 \pm 0.08$ & $2.63 \pm 0.11$ \\
Ammonium Nitrogen (NH $\left.{ }_{4}^{+}\right)$ & $\mathrm{g} / \mathrm{kg}$ & $3.51 \pm 0.12$ & $0.76 \pm 0.01$ & $1.74 \pm 0.54$ \\
Total Volatile Fatty Acids (TVFA) & $\mathrm{g} / \mathrm{L}$ & $0.90 \pm 0.10$ & ${ }^{\mathrm{a}} \mathrm{nd}$ & $3.61 \pm 0.11$ \\
\hline
\end{tabular}

${ }^{a}$ nd $=$ Not determined 
Table 2. Estimated parameters for anaerobic and microaerobic conditions

\begin{tabular}{llll}
\hline Parameter & Anaerobic & Microaerobic & $\mathbf{R}^{\mathbf{2}}$ \\
\hline$k_{0}(1 / \mathrm{d})$ & 0.1194 & & 0.9998 \\
$\boldsymbol{Y}_{c a r b, s o l}\left(\mathrm{~g}_{\text {carb, sol }} / \mathrm{g}_{\text {carb }, i s}\right)$ & 0.4337 & & \\
\hline$k_{0, a e}(1 / \mathrm{d})$ & & 1.0000 & \\
$K_{i, O 2}(\mathrm{~g} / \mathrm{L})$ & 0.4969 & 0.9898 \\
$K_{S, O 2}(\mathrm{~g} / \mathrm{L})$ & 0.7479 & \\
\hline
\end{tabular}




\section{Figures}
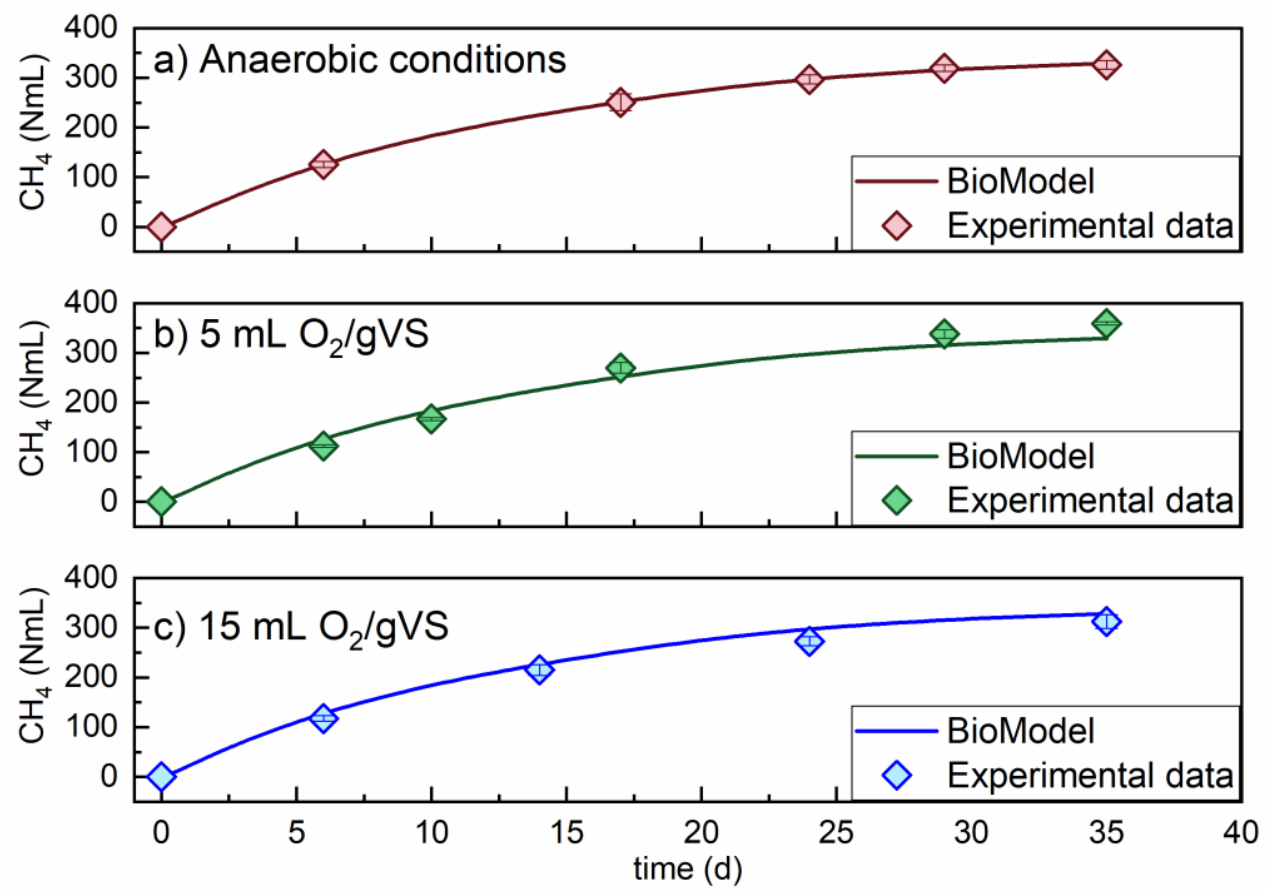

Fig. 1. Cumulative methane production for anaerobic and microaerobic conditions, respectively.

$\Lambda$ Experimental data; $\square$ BioModel output. 


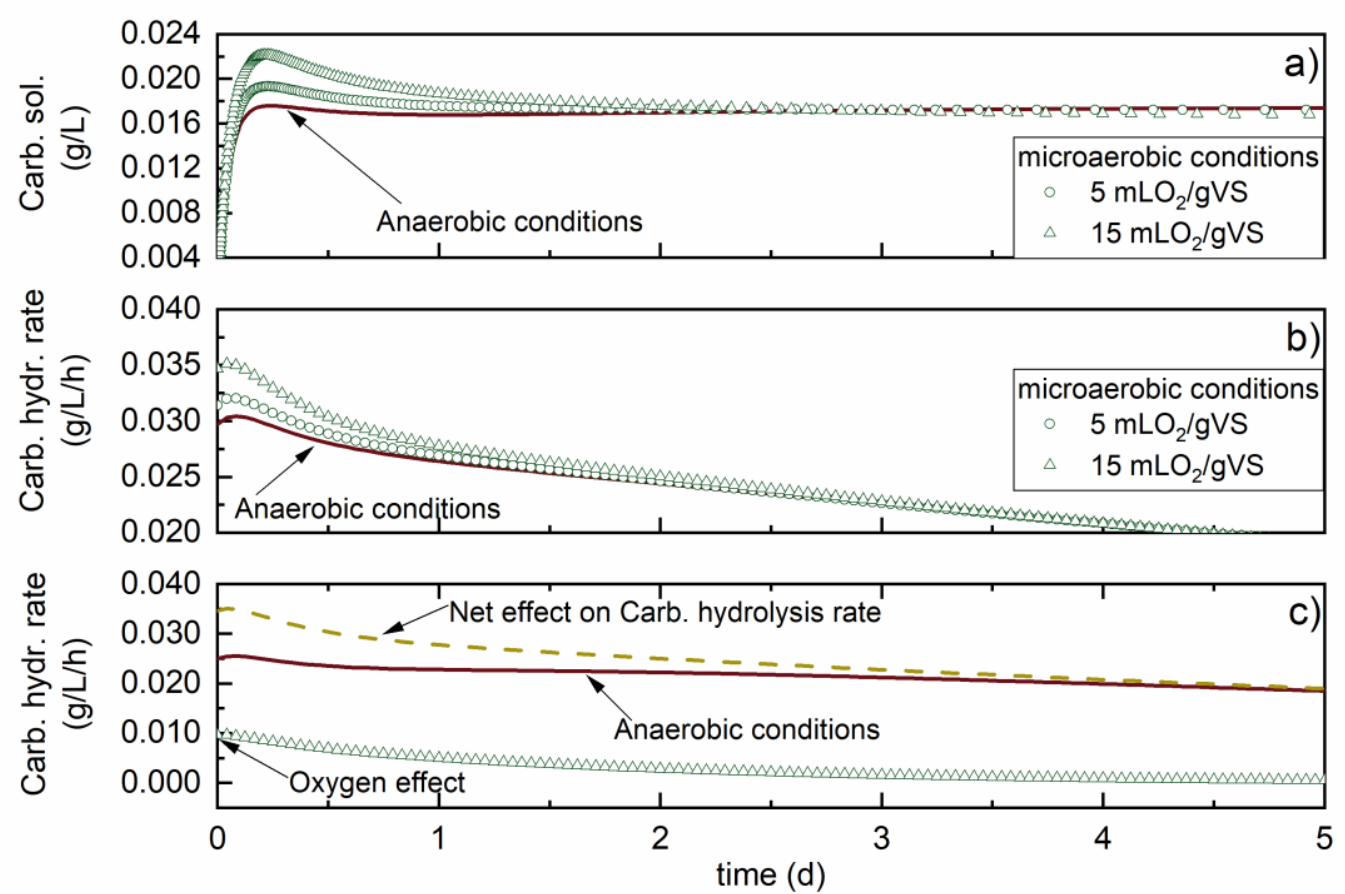

Fig. 2. Simulation results for: a) Concentration profile for soluble carbohydrates at anaerobic and microaerobic conditions, b) carbohydrate hydrolysis rate profiles and c) carbohydrate hydrolysis profiles for microaerobic conditions at $15 \mathrm{mLO}_{2} / \mathrm{gVS}$ 


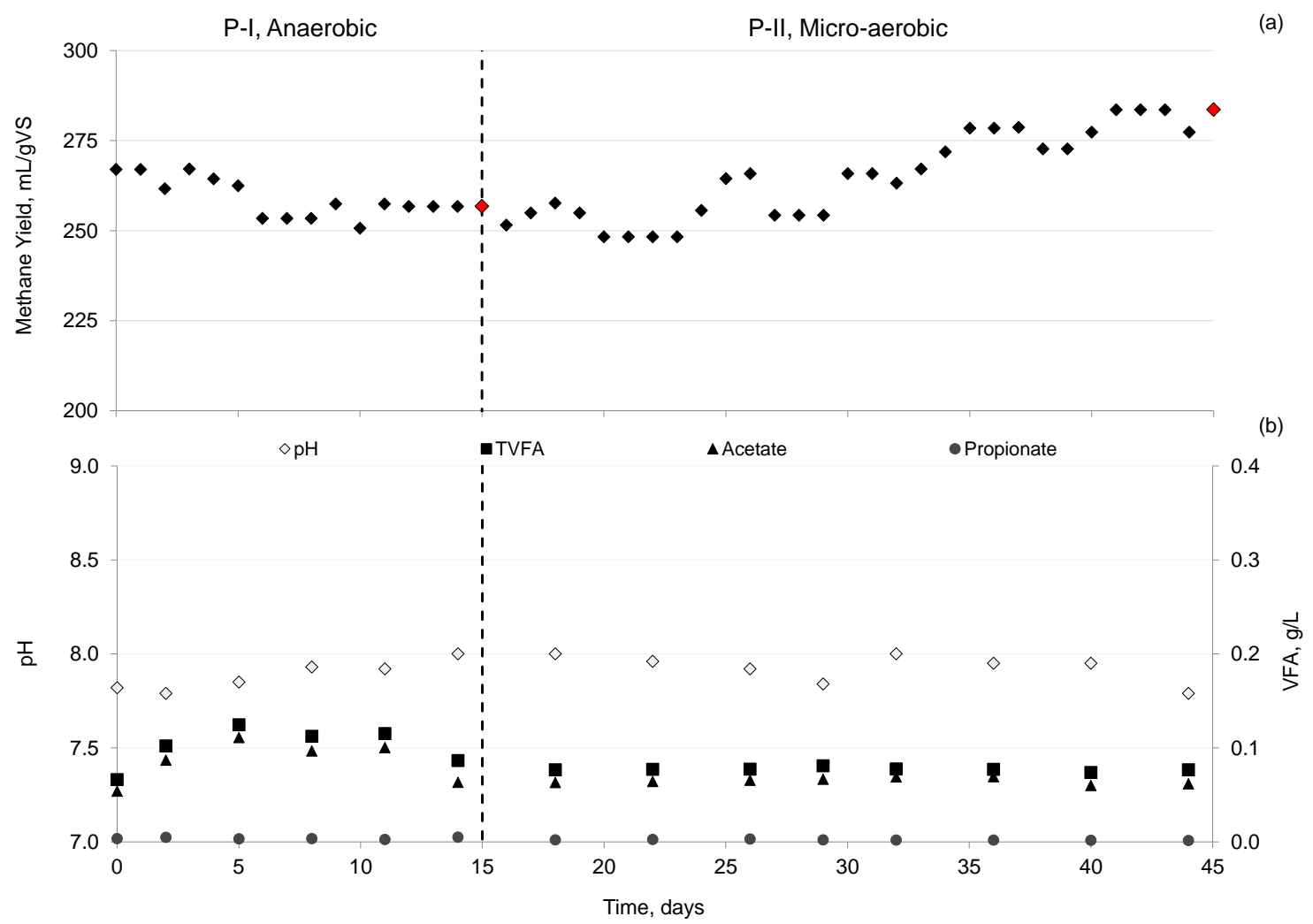

Fig. 3 Monitoring of continuous mode operation (a) methane yield and sampling points (red rhombus) for 16S rRNA gene analysis and (b) pH and VFA accumulation. 


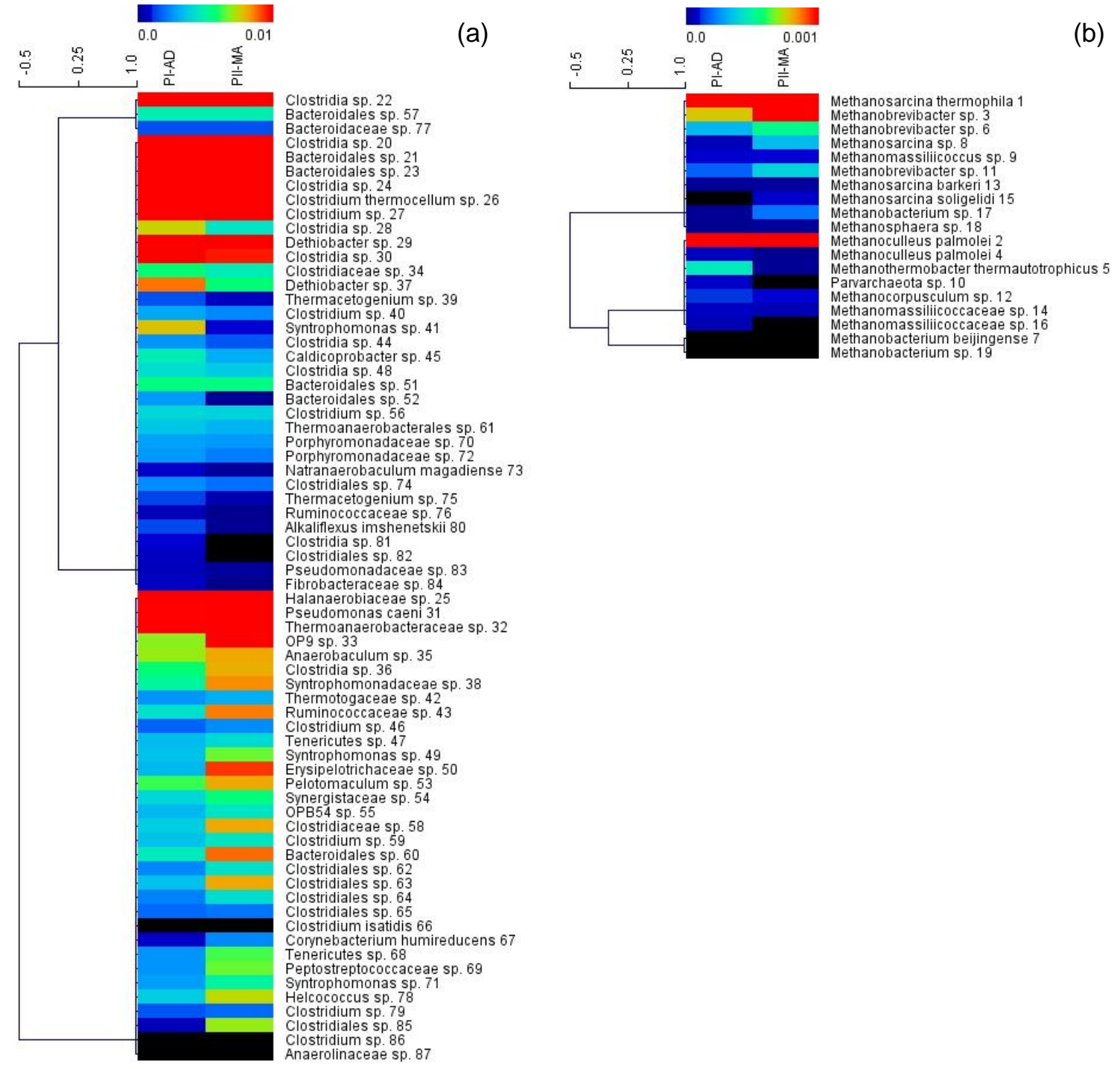

Fig. 4 Heat maps of relative abundance of most interesting (a) bacteria and (b) archaea. Colour scale refers to the OTUs abundance and is reported on top of the two figures. (For interpretation of the references to colour in this figure legend, the reader is referred to the web version of this article.) 